\section{Cosmetic approach of atrial septal defect repair through right anterolateral thoracotomy}

Atrial septal defect is one of the common cardiac malformations, approximately $6.7 \%{ }^{1}$. Although these malformation are often asymptomatic ${ }^{2}$, if uncorrected they may lead to irreversible pulmonary hypertension, progressively declining cardiac function and early death ${ }^{3}$. Secundum atrial septal defects occurs in 1 in 1500 live births, accounting for $10 \%$ to $15 \%$ of congenital heart defects in children and $20 \%$ to $40 \%$ of defects discovered in adults. A significant number of atrial septal defects close spontaneously within the first few years of life, but spontaneous closure after age 3 to 4 years is rare ${ }^{4}$. Report is documented that a few patients with atrial septal defect have survived into their 80 's $\mathrm{s}^{5}$. However most without correction die in the $4^{\text {th }}$ decade. $75 \%$ patients were died by the age 50 and $90 \%$ by age 60 . It is therefore recommended that patients with atrial septal defect, even though who are asymptomatic should undergo correction of the anomaly.

Currently, repair of atrial septal defects is considered a low risk and high beneficial procedure. The incidence being twice as great in female as in male patients, surgeons have always been inclined to find a cosmetically and psychologically more satisfying approach than the standard median sternotomy, considered by many as the gold standard approach ${ }^{6}$. In young girls closure of atrial septal defects through median sternotomy, often leaves an ugly scar on the anterior chest wall, which is cosmetically unacceptable. Modifications to avoid this scar lead to the use of a right anterolateral thoracotomy ${ }^{7}$, a posterolateral thoracotomy ${ }^{8}$ or a transxiphid approach without a sternotomy ${ }^{9}$. Among the different existing types of surgical access we preferred the right anterolateral thoracotomy approach because the surgical scar lies on the fold of the right breast. This cosmetic approach is essential for young women in our subcontinent as a social and religious custom particularly at the time of marriage. Keeping this idea in mind we tried and did successfully 166 operations during May 1997 to March 2009.

Before operation all patients were evaluated by New York Heart Association (NYHA) functional class. Out of 166 patients NYHA class I were 103, class II were $49 \&$ class III were 14 patients. The age range of patients was 12-30 years with mean age $18.34 \pm 4.57$ (mean $\pm \mathrm{SD}$ ) and all of them were female in gender. The decision to use a right anterolateral thoracotomy was directed by the desire of the patient or the patient's family for this cosmetic surgical approach.
After anesthetic induction, patients were placed in left lateral position with the right side elevated approximately $30^{\circ}$ and the right arm wrapped and hanging of the surgical table in a flexed position and the both legs were flexed about $25^{\circ}$ angles. Skin incision was made in the submammary fold and chest was entered through $4^{\text {th }}$ intercostal space. The right lung was deflated and pericardium was opened longitudinally anterior to the right phrenic nerve. Exposure was facilitated with stay sutures. In all cases the complete cannulation for cardiopulmonary bypass was performed via the same incision. The view of the aortic cannulation site was improved when the right auricle is pull down from ascending aorta by gentle traction of the auricle by a silk tie. Two aortic purse strings were placed proximally on the aorta and two caval purse strings were placed on the superior and inferior aspect of the right atrium. After heparinization, cannulation of the ascending aorta was achieved. Both superior and inferior vena cava were cannulated. Cardiopulmonary bypass was established and the caval tapes were snared. The aorta was cross clamped in all cases and cardioplegic arrest was induced by cold blood cardioplegic solutions through the root cardioplegic cannula. Right atriotomy was done and atrial septal defect was closed. Deairing of the cardiac cavities was done by giggling the heart and by resuming the ventilatory valsalva maneuver by root vent cannula. Patients were weaned from CPB, one drain was inserted in the pericardium and another one was inserted in the base of right pleural cavity. Pericardium was closed by keeping a rent in its lower part.

Patients were extubated $3.08 \pm 1.12$ hours in thoracotomy following surgery. Nine patients were extubated on the operating table and one patient was ventilated for 24 hours. The mean stay in intensive care unit was $2.08 \pm 0.58$ days. The mean hospital stay was $5.87 \pm 0.81$ days. The mean total operation time was $217.33 \pm 21.65 \mathrm{~min}$. The mean extracorporeal circulation time was $31.84 \pm 4.55$ min. Mean ischemic time was $13.92 \pm 5.44 \mathrm{~min}$. There were no major post-operative complications. Minor post-operative complications like only superficial wound infection were found in 2 patients. Early follow-up was available for all patients through clinical visits. Post-operative transthoracic echocardiography was performed for each patient before hospital discharge.

This study presents our early experience with the right anterolateral thoracotomy atrial septal defect repair. The major advantage of this approach is to avoid of sternotomy and its complications (mediastinitis, osteomyeltis etc.), and the ideal 
cosmetic results. Other advantages were less postoperative blood loss, shorter postoperative hospital stay and early return to pre-operative status than similar conventional surgery.

Cremer et al shows the same results ${ }^{10}$. Mulder and Vanermen pointed out that patient with an anterolateral thoracotomy for atrial septal defect closure has less pericardial adhesions, which is advantageous in case secondary operations for acquired heart diseases are necessary $5^{5}$.

Cost effectiveness was found less in anterolateral thoracotomy approach due to less ventilation time, less ICU stay, less hospital stay, less use of blood during and after procedure and early discharge from hospital. When assessing overall cost, a faster return to normal activity also has to be considered.

In our social and religious custom the atrial septal defect repair through right anterolateral thoracotomy is very much acceptable procedure than that of conventional median sternotomy.

Asit Baran Adhikary', Sarwar Kamal ${ }^{2}$, Sanjoy Kumar Saha $^{3}$, Aslam Hossain ${ }^{1}$, Sayed Abdul Quader ${ }^{2}$, Badruzzaman $^{2}$ and Prasanta Kumar Chanda ${ }^{4}$

${ }^{1}$ Department of Cardiothoracic Surgery, Bangabandhu Sheikh Mujib Medical University, Shahbag, Dhaka; ${ }^{2}$ Department of Cardiovascular Surgery, National Institute of Cardiovascular Diseases, Sher-E-Bangla Nagar, Dhaka; ${ }^{3}$ Department of Cardiac Anesthesia, Al-Helal Institute of Heart and Medical Science, Mirpur, Dhaka; ${ }^{4}$ National Heart Foundation \& Research Institute, Mirpur, Dhaka, Bangladesh. Tel: +88-01713000684; e-mail: drasit2005@yahoo.com

DOI: $10.3329 /$ bmrcb.v35i2.2766

\section{References}

1. Fulton DR. Congenital heart disease in children and adolescents. In: Hurst's the Heart. Fuster V, O'Rourke RA, Walsh RA, Poole-Wilson P. $12^{\text {th }}$ ed. China, McGraw-Hill Co., 2008, p 1855-1921.

2. Seldon WA, Rubstein C, Fraser AA, The incidence of atrial septal defect in adults. Br Heart J. 1962; 24: 55262.

3. Bonow R, Borer JS. Left ventricular functional reserve in adults with atrial septal defect: Pre- and postoperative studies. Circulation 1981; 63: 1315-22.

4. Bichell DP, Pelletier G. Atrial septal defect and cortriatriatum. In: Sabiston and Spencer surgery of the chest. Sellke WF, Nido DJP, Swanson SJ (eds). $7^{\text {th }}$ ed. Philadelphia, Anne Lenehan, 2005, pp 1931-44.

5. W. De Mulder, H Vanermen. Repair of atrial septal atrial septal defects via limited right anterolateral thoracotomy. Acta Chir Belg. 2002; 102: 450-54.
6. Grinda JM, Folliguet TA, Dervanian P, Mace L, Legault B, Neveux JY. Right anterolateral thoracotomy for repair of atrial septal defect. Ann Thorac Surg. 1996; 62: 175-78.

7. Massetti M, Babatasi G, Rossi A Operation for atrial septal defect through a right Anterolateral thoracotomy current outcome. Ann Thorac Surg. 1996; 62: 1100-03.

8. Yoshimura N, Yamaguahi M, Oshima Y. Repair of atrial septal defect through a right posterolateral thoracotomy: A cosmetic approach for female patients. Ann Thorac Surg. 2001; 72: 2103-05.

9. Barbero-Marcial M, Tanamati C, Jatene MB, Atik E, Jatene AD. Trans-xiphoid approach without median sternotomy for repair of atrial septal defects. Ann Thorac Surg. 1998; 65: 771-74.

10. Cremer JT, Boning A, Anssar MB. Different approaches for minimally invasive closure of atrial septal defects. Ann Thorac Surg. 1999; 67: 1648-52.

\section{Non-adherence to drug treatment in patients of essential hypertension}

We conducted a cross-sectional study on 120 patients (mean age $57 \pm 11$ years) of essential hypertension at Rajshahi Medical College Hospital and a private clinic. Approximately $69.2 \%$ of patients were males. The educational level varied; $32.5 \%$ had no education, $19.2 \%$ had a primary education, $29.2 \%$ had secondary or higher secondary education and $19.0 \%$ had a bachelor degree or higher. About one-fourth were unemployed. $77.5 \%$ were poor and earning $\leq$ 10,000 taka per month. The duration of disease ranged from 1 to 30 years and the antihypertensive drugs used by them were different (Table I). Eighty five percent of patients were non-adherent to treatment. The non-adherent patients had missed taking medication for anywhere from one day to the whole month.

Only $1.7 \%$ of patients had a good knowledge of the disease, side-effects of drugs and benefits of controlling blood pressure. Seventy five percent of patients knew that uncontrolled hypertension could lead to stroke and heart disease, one-third were aware it could lead to kidney failure. A few $(15.0 \%)$ knew hypertension can cause retinopathy and peripheral vascular disease (5.0\%). Only $3.3 \%$ of respondents had a good knowledge of the sideeffects of antihypertensive. One-third knew that exercise helps control blood pressure. Two-thirds of patients argued to change their medication only went for follow up visits when they felt hypertensive. Only one-third felt hypertension is not a curable disease. More than half believed the disease should cause certain signs and symptoms and another third were not sure. For the rest regarding understanding the disease, and benefits 